\title{
AVALIAÇÃO DO CONHECIMENTO DA POPULAÇÃO SOBRE O ANTIBIÓTICO AMOXICILINA
}

\section{EVALUATION OF POPULATION KNOWLEDGE OF AMOXICILLINE ANTIBIOTICS}

\author{
Viviane Pereira de Souza', Valdirene do Nascimento Santos'; Beatriz Essenfelder Borges ${ }^{1,2^{*}}$

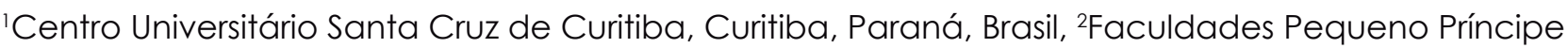 \\ de Curitiba, Curitiba, Paraná, Brasil \\ *Autor correspondente: Rua Amazonas 677, Água Verde, Curitiba. Telefone: 4199997531 1. Email: \\ biaessenfelder@gmail.com
}

\section{RESUMO}

As infecções são causadas pela invasão e multiplicação de micro-organismos, tais como: bactérias, vírus e fungos, dentro dos tecidos do nosso corpo, causando lesões no hospedeiro. Os antibióticos são substâncias químicas e sintéticas utilizadas no tratamento das infecções. A amoxicilina é um antimicrobiano $\beta$-lactâmico, cuja ação é bactericida, ou seja, interfere na parede celular das bactérias impedindo seu crescimento. Diante disso, o objetivo desta pesquisa foi identificar se os pacientes, usuários de uma Unidade de Saúde de Curitiba, têm conhecimento sobre o uso correto do antibiótico amoxicilina e os malefícios que o uso incorreto pode ocasionar. Metodologia: Estudo de delineamento transversal, em uma Unidade de Saúde de Curitiba/PR, por meio da aplicação de um formulário com vinte e seis questões relacionadas ao uso do antibiótico. A escolha da amoxicilina deu-se pelo fato de a Unidade de Saúde prescrever com maior frequência esse medicamento. A amostra foi de 104 usuários da Unidade de Saúde ( $n=104)$. Identificou-se que a população pesquisada utiliza o antibiótico amoxicilina para sintomas de dores e inflamação, além de interromper o tratamento medicamentoso assim que ocorre a melhora do quadro clínico. Ressalta-se que os pacientes realizam a prática de automedicação quando compram o fármaco, sem receita médica e/ou odontológica e, sobretudo, desconhecem os malefícios do uso incorreto desse antimicrobiano à sua saúde, tendo como consequência a resistência bacteriana. Constatou-se que, as políticas públicas de saúde deveriam trabalhar de forma conjunta com os profissionais, visando à educação em saúde para a população, com o intuito de promoção do autocuidado e conscientização a respeito do uso dos antibióticos.

Palavras-chave: Antibacterianos; Resistência microbiana a medicamentos; Automedicação.

\section{ABSTRACT}

Infections are caused by an invasion and multiplication of microorganisms within the tissues of our body, such as bacteria, viruses and fungi that cause damage to the host. Antibiotics are chemical and synthetic substances that are used to treat infections. Amoxicillin is a $\beta$-lactam antimicrobial, whose action is bactericidal, that is, they interfere with the bacterial cell wall preventing its growth. The aim of this study was to identify whether patients from a Health Unit in Curitiba are aware of the use of the antibiotic amoxicillin and the harm that incorrect use can cause. Methodology: Cross-sectional study in a Health Unit in Curitiba/PR, using a form with twenty-six questions related to the use of antibiotics. The choice of amoxicillin was due to the fact 
that the Health Unit prescribes this medication more frequently. The sample consisted of 104 users of the Health Unit $(n=104)$. It was identified that the researched population uses the antibiotic amoxicillin for symptoms of pain and inflammation, in addition to interrupting drug treatment when the clinical condition improves. It should be stressed that patients practice self-medication when they buy the drug without a prescription and / or dentistry, above all, they do not know the harm that they do to their health when they do not use the antimicrobial correctly, and a consequence of this attitude is bacterial resistance. It was observed that public health policies should work together with professionals to develop health education for the population in order to promote self-care and raise awareness about the use of antibiotics.

Keywords: Antibacterials; Microbial drug resistance; Self-medication.

\section{INTRODUÇÃO}

As infecções são causadas pela invasão e multiplicação de micro-organismos, tais como: bactérias, vírus e fungos, dentro dos tecidos do nosso corpo, causando lesões no hospedeiro (WOKSEPP, 2017).

Os antibióticos são substâncias químicas e sintéticas utilizadas no tratamento das infecções (SANTOS, et al. 2017).

Dentro da classe das penicilinas tem-se a amoxicilina, um antimicrobiano $\beta$-lactâmico, cuja ação é bactericida, ou seja, interfere na síntese da parede celular das bactérias impedindo seu crescimento (REIS, 2015).

A amoxicilina atua tanto no combate das bactérias Gram-positivas aeróbias, tais como: Enterococus faecalis, Streptococcus pneumoniae e Staphylococcus aureus, quanto nas Gram-negativas, exemplificadas por Hemophilus influenzae, Escherichia colli e Helicobacter pylory. É administrada via oral, seu metabolismo de ação e excreção é via renal, onde cerca de 60\% a 70\% é excretado inalterado na urina, é indicado para infecções urinárias, respiratórias e profiláticas (REIS, 2015). A amoxicilina 500mg apresenta posologia padrão para o tratamento de infecções, seu tratamento geralmente dura sete dias totalizando o uso de vinte e uma cápsulas (FONSECA, 1984).

O mau uso do antibiótico interfere no tratamento do paciente, causando grandes malefícios, sobretudo, a resistência bacteriana, que ocorre quando a bactéria, antes suscetível ao princípio ativo do medicamento, passa a sobreviver e a se multiplicar tornando-se resistente, devido a isso há a necessidade de prescrição de um princípio ativo mais potente. Desse modo, o antibiótico que, anteriormente, era eficaz, deixa de ser útil e a bactéria torna-se ainda mais perigosa, causando inclusive doenças de difícil tratamento, o que pode ocasionar risco de morte em pessoas imunodeprimidas, que possam entrar em contato com essas cepas resistentes (COSTA, et al. 2017).

No caso das penicilinas a resistência ocorre devido à produção de uma enzima $\beta$-lactamase que hidrolisa o anel $\beta$-lactâmico do antibiótico, e as bactérias Gram-positivas e Gram-negativas têm a transferência de plasmídeos (moléculas circulantes do DNA), que codificam a resistência a múltiplos antibióticos. A multiplicação desse micro-organismo levará a disseminação aumentada dos genes de resistência (NOGUEIRA, et al. 2016; WOKSEPP, 2017). 
O uso indiscriminado e os gastos desnecessários com a compra dos antibióticos são assuntos que preocupam os profissionais de saúde e as autoridades sanitárias, pois estão acarretando prejuízos à saúde da população, uma vez que, quando os antibióticos são utilizados de forma incorreta podem esconder alguns sintomas de uma determinada patologia e agravar o quadro clínico do indivíduo. E não se pode deixar de citar que os medicamentos, em geral, apresentam alguns efeitos adversos como: alergias, intoxicações, interações medicamentosas e podem favorecer a resistência bacteriana (ZUTION, et al. 2017).

São frequentes os registros na literatura médica sobre o uso indiscriminado de antibióticos, de amplo espectro, pela população em geral. Devido à cultura popular brasileira é comum que as pessoas adquiram o medicamento com vizinhos, comprem sem prescrição médica e, ainda, que iniciem o tratamento medicamentoso com as doses que "sobraram" da terapêutica anterior. Sabe-se que essa prática pode ocasionar diversos malefícios ao indivíduo (TRINDADE, et al. 2017).

Diante dos fatores mencionados, o objetivo desta pesquisa foi identificar se os pacientes, usuários de uma Unidade de Saúde de Curitiba, têm conhecimento sobre o uso correto do antibiótico amoxicilina e os malefícios que o uso incorreto pode ocasionar.

\section{METODOLOGIA}

Esta pesquisa pode ser classificada como um estudo descritivo de delineamento transversal, desenvolvida em uma Unidade de Saúde de Curitiba/PR, submetida e aprovada pelo Comitê de Ética em Pesquisa em Seres Humanos do Hospital Paranaense de Otorrinolaringologia, sob o parecer de aprovação $n^{\circ} 3.400 .533$.

A população de estudo foi composta por 104 usuários, com cadastro definitivo na Unidade de Saúde, todos maiores de 18 anos (entre adultos e idosos), classificados nacionalmente pelo Estatuto da Juventude e Estatuto do Idoso, categorizados por dados sociodemográficos (BRASIL, 2003; BRASIL, 2013). Dentro do critério de inclusão, os usuários e participantes da pesquisa deveriam ter cadastro definitivo na Unidade de Saúde, dentre os quais realizaram o tratamento com antibiótico.

Foi entregue aos participantes da pesquisa um formulário contendo 26 questões, com informações sociodemográficas, relacionadas ao conhecimento acerca do antibiótico amoxicilina, isso após terem concordado e assinado o Termo de Consentimento Livre e Esclarecido (TCLE). Os dados coletados foram dispostos em blocos distintos, contendo as variáveis indicadas pelo questionário. As 8 primeiras questões refletiram a respeito do perfil sociodemográfico da amostra e as demais referiram-se ao uso correto do medicamento.

A coleta de dados ocorreu de segunda a sexta-feira, das $8 \mathrm{~h}$ às $16 \mathrm{~h}$, durante o mês de agosto de 2019, na recepção da Unidade de Saúde selecionada.

\section{RESULTADOS E DISCUSSÃO}

Como evidencia a tabela 1 , observamos o perfil da população de estudo, o qual nos trouxe dados sociodemográficos. A amostra foi composta por 104 usuários de uma Unidade de Saúde $(n=104)$ e os resultados, em sua análise, estão representados em porcentagem (\%). 
Tabela 1 - Dados sociodemográficos

\begin{tabular}{|c|c|c|c|}
\hline CATEGORIAS & SUBCATEGORIAS & $n=104$ & $\%$ \\
\hline \multirow{2}{*}{ GÊNERO } & Feminino & 77 & 74 \\
\hline & Masculino & 27 & 26 \\
\hline \multirow{2}{*}{ IDADE } & 18 a 59 anos & 88 & 85 \\
\hline & Acima de 60 anos & 16 & 15 \\
\hline \multirow{4}{*}{ ESTADO CIVIL } & Solteiro & 34 & 33 \\
\hline & Casado & 60 & 58 \\
\hline & Divorciado & 4 & 4 \\
\hline & Viúvo & 6 & 6 \\
\hline \multirow{4}{*}{ FILHOS } & 1 a 3 & 68 & 65 \\
\hline & 4 a 6 & 12 & 11 \\
\hline & 7 a 9 & 3 & 3 \\
\hline & Não possui & 21 & 15 \\
\hline \multirow{6}{*}{ ESCOLARIDADE } & Fundamental Incompleto & 25 & 24 \\
\hline & Fundamental Completo & 16 & 15 \\
\hline & Médio Incompleto & 16 & 15 \\
\hline & Médio Completo & 35 & 34 \\
\hline & Superior Incompleto & 4 & 4 \\
\hline & Superior Completo & 8 & 8 \\
\hline
\end{tabular}

Fonte: Autora, 2019.

Segundo Trindade e colaboradores, 2017, o gênero feminino representa 74\% da população pesquisada, em sua amostra, o que representa um dado interessante, evidenciando que as mulheres procuram mais os serviços de saúde que os homens. Isso também foi observado na população do presente estudo, o qual demonstrou que, o gênero feminino constituiu $74 \%$ dos pesquisados, fato que pode estar relacionado às mulheres procurar mais as Unidades de Saúde. Ainda, de acordo com Trindade e colaboradores, 2017, a escolaridade e o percentual de quem completou o ensino médio é muito semelhante quando comparado à nossa amostra, ambos os estudos revelam que, a maioria não possui nível superior.

Após a coleta de dados, também foi observado que 100\% dos entrevistados residíamos no bairro onde se localizava a Unidade de Saúde. A amostra revelou que 63,4\% moram na região há mais de 15 anos, sendo que 86,5\%, da população pesquisada, são dependentes exclusivos do Sistema Único de Saúde (SUS).

Fernandes, et al. (2009) ressaltam que o SUS é ofertado a toda a população, independentemente da classe social. Ao analisar os dados de sua pesquisa observou-se que, os cidadãos que utilizam o serviço de saúde, próximo à sua residência, são aqueles que não possuem plano de saúde, portanto, equipara-se à população de baixa renda e desempregados. Segundo o autor, cada município é responsável pelo atendimento integral aos usuários do SUS, e os gestores têm que estar atentos às necessidades de saúde da sua população, observando os determinantes sociais de saúde da sua região (FERNANDES, et al. 2009).

Ainda analisando os resultados, a pesquisa demonstra que $87,6 \%$ da população pesquisada utiliza a US como recurso terapêutico, a fim de restabelecer a sua saúde física e/ou mental. E, dentro desse grupo, 92,3\% faz tratamento médico, enquanto que 82,6\% acessam as consultas odontológicas. 
Dentro da amostra, no que tange às consultas odontológicas, $26,9 \%$ procurou o serviço devido a uma emergência e 52,8\% para consultas de rotina.

Segundo dados do site da Secretaria Municipal de Saúde de Curitiba (2019), o município de Curitiba presta assistência integral à saúde da população, por meio da Atenção Primária de Saúde (APS), que é um conjunto de práticas integrais de saúde que procuram atender às necessidades individuais e coletivas da população. De acordo com a logística temos 111 Unidades de Saúde no município, distribuídas em 10 Distritos Sanitários e/ou Regionais, das quais as Unidades de Saúde (US) fazem parte, sendo 64 denominadas Estratégias da Saúde da Família (ESF) e 47 Unidades Básicas de Saúde (UBS). Os profissionais de saúde que compõem as equipes, as quais trabalham nas unidades de saúde, tem a responsabilidade de prestar assistência à população dentro do seu território, definido em sua área de abrangência.

A população brasileira que procura as unidades de saúde, para realizar tratamento de saúde, muitas vezes apresenta alguns sintomas relacionados à afecção, como dores, inflamações ou até mesmo infecções.

Em algum momento esses indivíduos têm que fazer tratamento medicamentoso para a cura de uma determinada doença. Devido a isso fizemos a seguinte pergunta para os participantes da pesquisa: Quando foi necessário tomar remédio, foi com intuito de tratar uma doença? O gráfico 1, mostrado abaixo, nos traz os resultados.

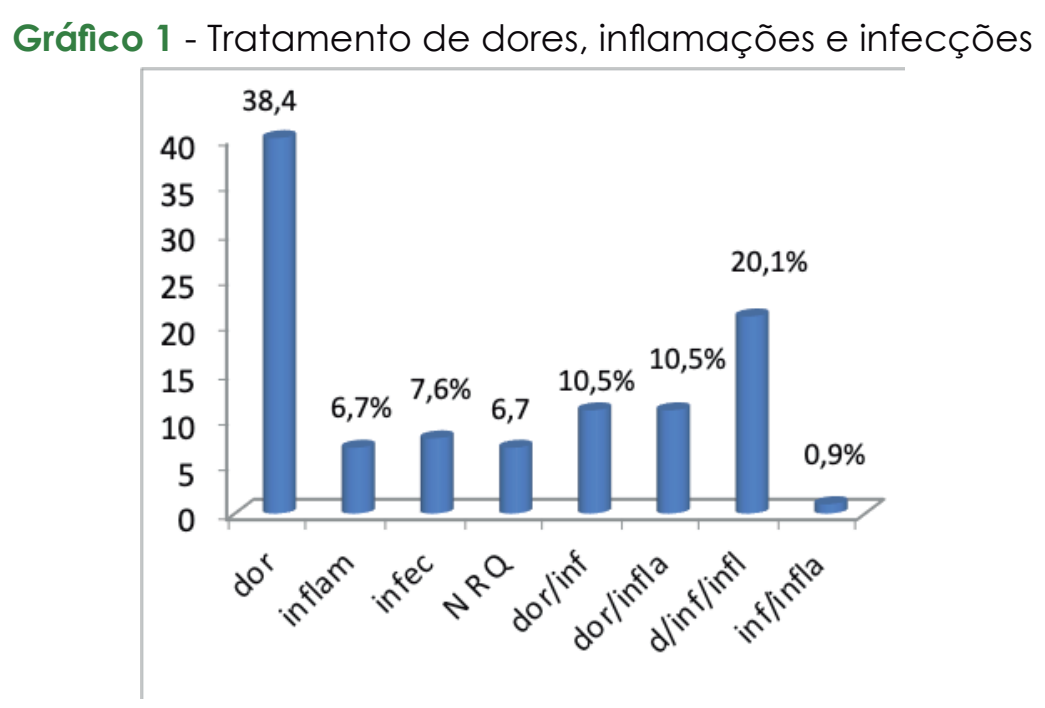

Fonte: Autora, 2019.

Com base no gráfico acima, fica evidente que 38,4\% dos pacientes afirmaram fazer tratamento para dor, 6,7 \% dos entrevistados não responderam à questão (N.R.Q.). Segundo SILVA, et al. (2015), a dor é um sintoma que o ser humano apresenta quando há lesão tecidual ou potencial, esse sintoma tem função protetora em nosso organismo, porém, quando não tratada causa sofrimento e é considerada um problema de saúde pública, isso em escala mundial.

De acordo com Lima et al. (2007), a inflamação é a defesa do organismo, a qual ocorre após dano celular causado por micróbios, ou seja, incide o aumento do fluxo sanguíneo na região afetada e as células de defesa atuam para nos proteger contra patógenos. Em nossa pesquisa, o percentual de quem realizou tratamento para inflamações foi de $6,7 \%$. 
A porcentagem de quem precisou sanar infecções foi de $7,6 \%$, infecções essas causadas pela invasão e multiplicação de micro-organismos, dentro dos tecidos do nosso corpo, tais como: bactérias, vírus e fungos, os quais são capazes de causar lesões no hospedeiro (WOKSEPP, 2017).

Ainda, analisando a figura acima, a amostra evidenciou que, 20,1\% dos usuários, afirmaram tomar remédios para tratar os três sintomas presentes em sua doença. Uma das possibilidades encontradas para entender desse resultado é que a população, talvez, não saiba a diferença entre infecção, inflamação e dor, no entanto, quando questionados, os pesquisados responderam à diferença de forma correta.

Como podemos perceber o percentual dos pacientes que fazem tratamento para dores é elevado. Assim, questionamos quais são os medicamentos utilizados para o alívio da dor, os resultados observam-se no gráfico abaixo.

Gráfico 2 - Fármacos utilizados para alívio da dor

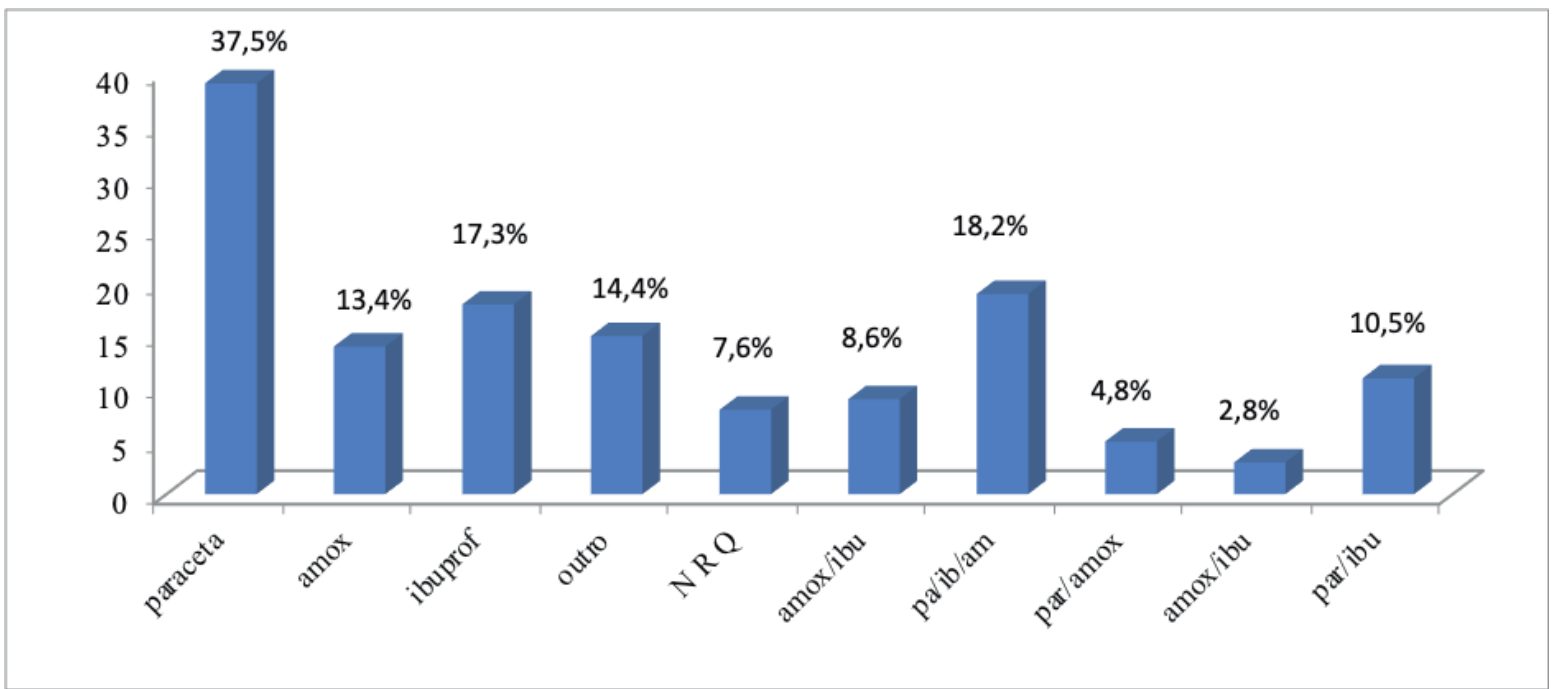

Fonte: Autora, 2019.

Esses dados mostram que grande parte da população pesquisada utiliza os medicamentos de forma errônea, pois 13,4\% disseram utilizar amoxicilina, que é um antibiótico, para tratar dores. Isso é muito preocupante, pois estão realizando o tratamento com um fármaco destinado à cura de infecções.

A amoxicilina é um antibiótico de amplo espectro e apresenta resultados satisfatórios, quando receitado de forma correta, e sua eficácia é de 90\% durante o tratamento das infecções (TRINDADE, et al. 2017).

Como pudemos verificar em nossa amostra, por meio da análise de dados, os pacientes utilizaram o fármaco como analgésico.

Para Santos, et al. (2017), os antibióticos são substâncias químicas e sintéticas utilizadas para o tratamento de infecções e $63,42 \%$ da sua população de estudo tem o conhecimento de que o fármaco é utilizado no tratamento de infecções bacterianas.

Para saber se a população tem o devido conhecimento sobre o que é um antibiótico fizemos a seguinte pergunta: Você sabe para que serve o antibiótico? Os resultados estão expressos no gráfico a seguir. 
Gráfico 3 - Conhecimento acerca do antibiótico

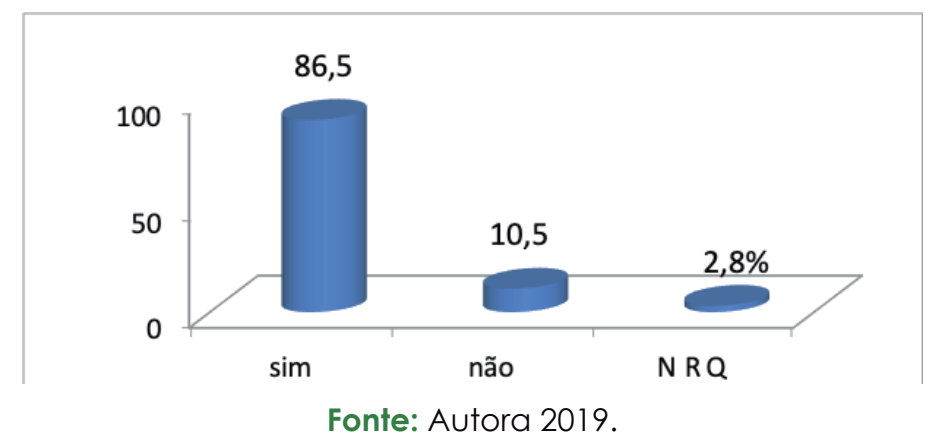

Conforme a análise, $86,5 \%$ dos participantes responderam que sabem para que serve o antibiótico, porém, essa pergunta não nos mostrou, de fato, o conhecimento que os indivíduos possuem a respeito do medicamento. Assim sendo, perguntamos em seguida para qual finalidade o antibiótico foi utilizado, observamos então uma discrepância nos resultados e descobrimos que os pacientes utilizavam o antibiótico para tratamento de inflamações e não para a finalidade a qual ele se destina. Dos participantes, 26,9\% utilizaram para inflamação, como demonstrado no gráfico 4.

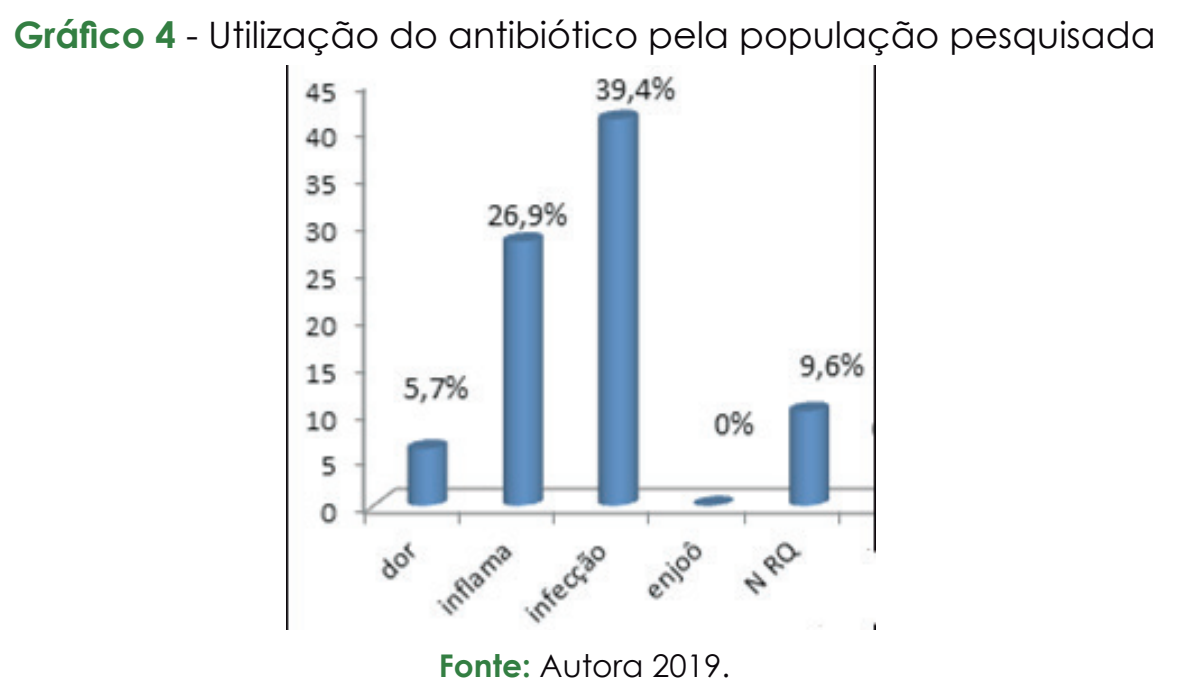

De acordo com um estudo de Trindade et al. (2017), o porcentual dos que não possuíam conhecimento da utilidade do antimicrobiano foi de $57 \%$, o que os autores consideraram um problema de saúde pública em nosso país. Na pesquisa de Lopes et al. (2015), a população utiliza o antibiótico para tratamentos de amigdalites, dores de garganta, dores de dentes, gripes e infecções urinárias. As amostras nos mostram que ambas as populações de estudo estão sujeitas à iatrogenia em seu tratamento de saúde.

A farmácia dentro das Unidades de Saúde, em Curitiba, dispõe de vários medicamentos para tratamento de saúde de seus usuários. Os fármacos antimicrobianos fazem parte dessa distribuição, são eles: sulfametoxazol, benzilpenicina (benzetacil), cefalexina (somente para gestantes), gentamicina (colírio), ceftriaxona e amoxicilina com clavulanato (suspensão). A amoxicilina (comprimido) é um dos mais receitados para combater as infecções, por isso vimos a necessidade de saber se a população, de estudo, fez uso dessa medicação corretamente (Secretaria Municipal de Saúde de Curitiba, 2019).

Quando foram indagados se tomavam o remédio, conforme a prescrição médica, 86,5\% dos entrevistados disse que sim, porém, não é o que comprova o gráfico abaixo. 
Gráfico 5 - Tempo de utilização do medicamento. Você tomou o antibiótico amoxicilina por quanto tempo?

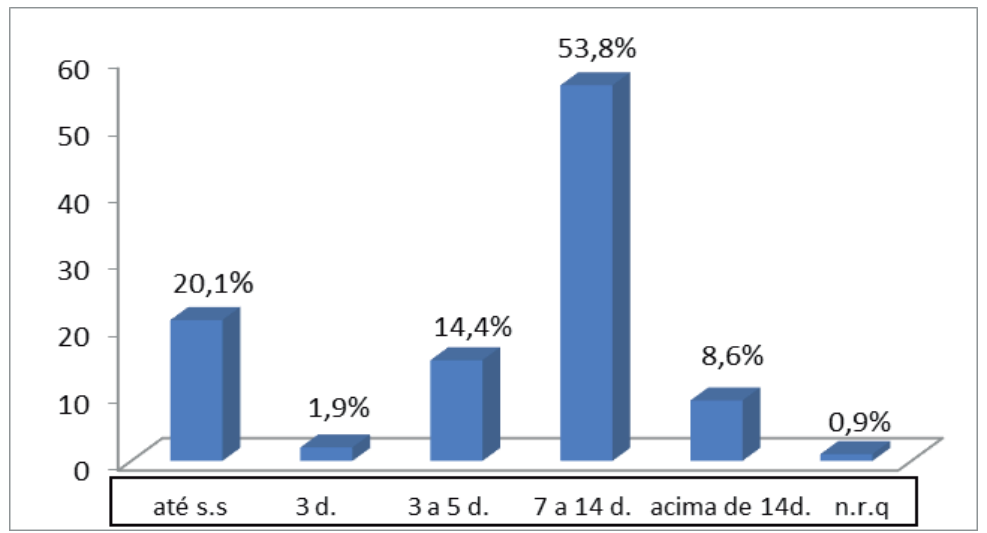

Fonte: Autora, 2019.

Os antibióticos são medicamentos que só podem ser utilizados com prescrição médica e/ou odontológica, conforme posologia indicada, e nos estritos termos da prescrição (TRINDADE, et al. 2017).

A amoxicilina 500mg apresenta posologia padrão para o tratamento de infecções e seu tratamento, geralmente, é de sete dias, totalizando o uso de vinte e uma cápsulas (FONSECA, 1984).

O indivíduo que utiliza um antibiótico inadequado, em dosagens diferentes da prescrição ou que interrompe o tratamento sem recomendação médica, se coloca em risco, uma vez que essas ações podem agravar a infecção e ocasionar o processo de seleção de bactérias resistentes, podendo tornar o uso do antibiótico ineficaz, no caso de uma nova infecção (CASTILHO; OLIVEIRA, 2015).

Como observado no gráfico $5,20,1 \%$ da população toma o medicamento até que os sintomas sumam (s.s) e 14,4\% fazem uso pelo período de 3 a 5 dias, demonstrando um dado alarmante de que, às vezes, o paciente tenha de repetir o tratamento.

O uso indiscriminado dos antibióticos é um assunto que preocupa os profissionais de saúde e as autoridades sanitárias, pois pode trazer prejuízos à saúde da população (ZUTION et al.; 2017). Perguntamos à nossa população de estudo, quantas vezes tinham usado o antibiótico amoxicilina no ano de 2019. O resultado consta no gráfico a seguir.

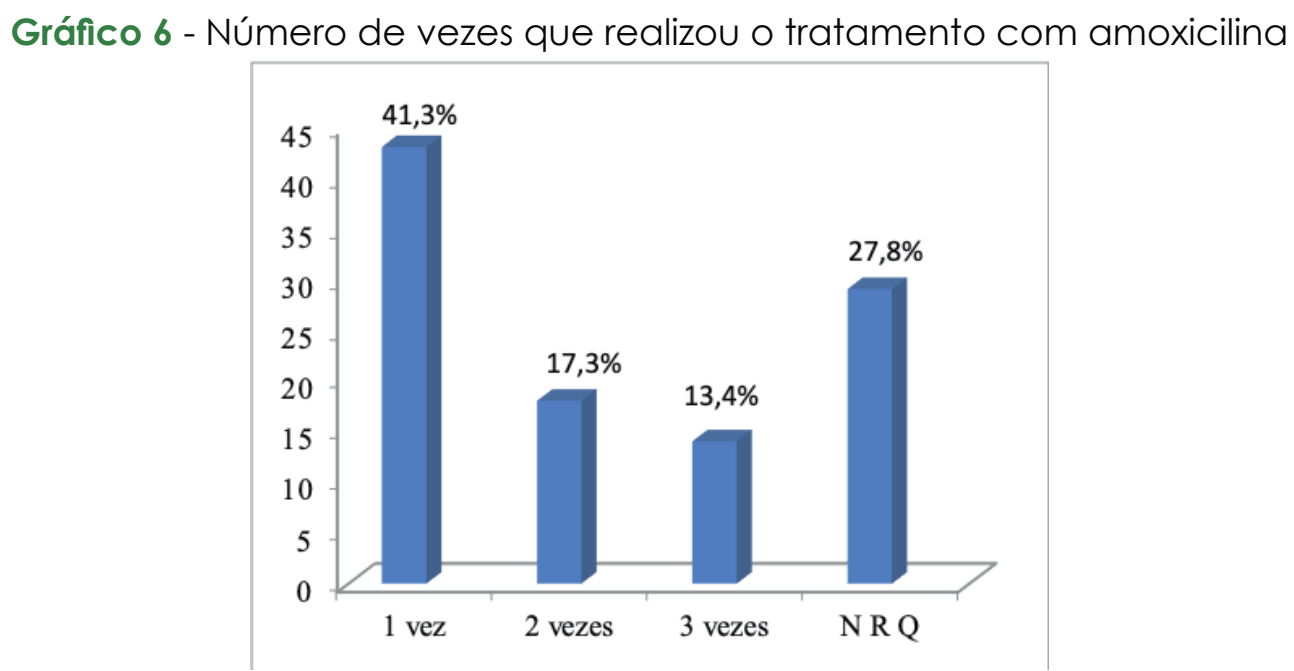

Fonte: Autora, 2019. 
De acordo com Costa e Silva Junior (2017), a resistência bacteriana pode ocorrer se utilizarmos o fármaco de forma inadequada, ou para uma condição de saúde que não seja a de infecção. Um fator que colabora para que isso aconteça é que profissionais de saúde, muitas vezes, prescrevam as medicações baseados em sinais e sintomas sem fundamentação de culturas microbianas. Em nossa amostra, o percentual dos pacientes, que tiveram que repetir a antibioticoterapia dentro de 1 ano, foi muito elevado.

Os relatos de automedicação com amoxicilina sugerem o uso incorreto do antimicrobiano com interrupção precoce do tratamento, fator diretamente ligado à resistência bacteriana. Além disso, o fornecimento de sobras de tratamento a terceiros fomenta a automedicação, prática que agrava a resistência bacteriana e que pode acarretar diversos efeitos colaterais danosos ao uso abusivo de antibióticos. Na tabela 2, veremos como os usuários adquirem o fármaco, pois nos chamou a atenção que 13,4\% dos entrevistados tenham relatado o uso do medicamento por três vezes, até aquele momento.

Tabela 2 - Como adquiriu o antibiótico

\begin{tabular}{l|l} 
Forma de adesão & Porcentagem \\
\hline Receita médica e /ou odontológica & $72,1 \%$ \\
\hline Comprou na farmácia sem receita & $11,9 \%$ \\
\hline Sobra do tratamento anterior & $6,6 \%$ \\
\hline Não responderam à questão & $13,4 \%$ \\
\hline \multicolumn{2}{r}{ Fonte: Autora, 2019.}
\end{tabular}

Ao analisarmos os resultados, pudemos perceber que a utilização do antibiótico nem sempre aconteceu com prescrição. Podemos averiguar que a população ainda tem a cultura de comprar medicação sem a receita médica, prática realizada por mais de 11\% dos entrevistados.

A venda desses medicamentos é controlada, pois se exige a retenção do receituário. Porém, são comuns relatos de obtenção do medicamento sem receita em farmácias, com amigos e parentes, e sobras de medicamentos nas residências, devido a tratamentos interrompidos (TRINDADE, et al. 2017).

De acordo com Nascimento e Valdão (2012), a população brasileira identifica a farmácia como um recurso para solucionar seu problema de saúde e isso é caracterizado como automedicação. Em sua amostra verificou que as pessoas que adquirem medicamentos, sem passar por uma consulta médica e/ou odontológica, são aquelas que possuem um nível de escolaridade maior e são as mesmas que afirmam ter conhecimento suficiente para resolver seu problema de saúde.

Neste estudo vimos que os idosos, os quais representam 15\% da população entrevistada, não fazem uso dos medicamentos sem consultar e seguem todas as orientações a respeito de como realizar o tratamento medicamentoso, o que consideramos um dado importante, devido à baixa escolaridade, (ensino fundamental incompleto).

Outro dado importante é que a população de estudo, 78,4\% admitiu ter sido orientada pelos profissionais de saúde sobre o uso correto dos antibióticos, referente à posologia, ou seja, a quantidade de dias, as doses e os horários que os pacientes teriam de seguir em seu tratamento medicamentoso para obter um resultado satisfatório. 
Quando foram questionados se realizavam corretamente o tratamento, em se tratando dos horários, houve um percentual elevado dos usuários que "esqueceram" de tomar a medicação no horário sugerido. Como demonstra o gráfico 7.

\section{Gráfico 7 - Esqueceu-se de tomar a amoxicilina no horário sugerido?}

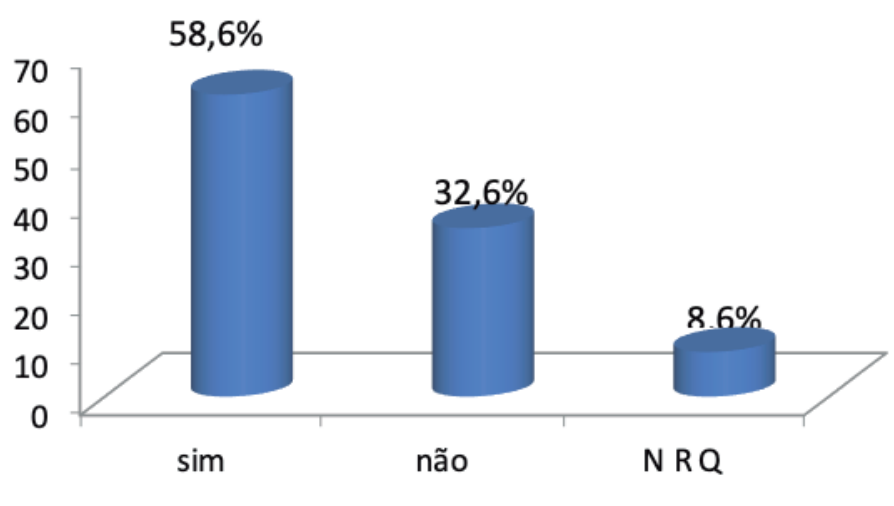

Fonte: Autora, 2019.

Em nossa amostra, observou-se que $58,6 \%$ da população de estudo não seguia as orientações da prescrição médica e, por algum motivo, não tomava a medicação no horário sugerido. De acordo com Matos (2012), os doentes esquecem-se de tomar o medicamento no horário sugerido e/ou interrompem o tratamento quando sentem melhora no quadro clínico. Esse comportamento traz consequências à sua saúde, pois fornece condições para que os micro-organismos se adaptem em vez de serem eliminados. Considera ainda que a prescrição antibiótica deve ser vista como um ato médico, devido à sua terapêutica e tem de ser ponderada quanto aos seus riscos e benefícios.

\section{CONCLUSÃO}

Concluiu-se que, a população de estudo não tem conhecimento sobre a finalidade dos antibióticos, e tampouco para quais sintomas eles devem ser usados. Há um percentual elevado de usuários que utilizam o medicamento com o intuito de aliviar manifestações clínicas como dores e inflamações. Portanto, considera-se um dever de todos os profissionais de saúde orientar a população sobre a indicação de uso correto dos antibióticos.

Os antibióticos são medicamentos de suma importância no combate a infecções. A amoxicilina é um antimicrobiano com eficácia de $90 \%$, pois elimina o micro-organismo causador do quadro infeccioso. Porém, quando o indivíduo não consegue realizar o tratamento de forma adequada coloca em risco a sua saúde e a saúde de toda a população, trazendo consequências como a resistência bacteriana.

Quando os indivíduos não compreendem que as medicações, em geral, precisam seguir a posologia correta referente aos dias, às doses e aos horários, infelizmente o medicamento prescrito não terá o efeito desejado no tratamento indicado para sua condição de saúde e o organismo não conseguirá combater os micro-organismos causadores das doenças.

Os profissionais de saúde precisam estar atentos à terapêutica medicamentosa dos pacientes, procurando orientá-los sobre o uso correto do antimicrobiano, explicando o motivo pelo qual não 
se deve interromper o tratamento e, ainda, ressaltar que não se deve adquirir o medicamento sem prescrição médica e/ou odontológica.

O uso indiscriminado dos antibióticos pode ser considerado um sério problema de saúde pública e a cultura brasileira da automedicação é um fator que contribui para a piora da situação, o que também pode ser agravado, por parte dos profissionais, quando prescrevem os antibióticos de forma errônea.

Por meio deste estudo constatou-se a necessidade de fomento de políticas públicas de saúde, engajadas aos profissionais de saúde, desenvolvendo educação em saúde à população, com o intuito de promover o autocuidado e a conscientização a respeito do uso correto dos antibióticos.

\section{REFERÊNCIAS BIBLIOGRÁFICAS}

ANTONIO, N.S. OLIVEIRA, A.C., CANESINI, R., ROCHA, J.R., Mecanismos de resistência bacteriana. Revista FAEF. São Paulo: Garça, 2009.

BRASIL. Estatuto da juventude: lei n 12.852, de 5 de agosto de 2013. Brasília, DF: Secretaria Especial dos Direitos Humanos, 2013.

BRASIL. Estatuto do idoso: lei federal n 10.741, de 01 de outubro de 2003. Brasília, DF: Secretaria Especial dos Direitos Humanos, 2003.

CASTILHO, B.N.; OLIVEIRA, J. Análise de prescrições de amoxicilina, azitromicina e cefalexina em pediatria nos municípios de Guaratinguetá-SP e Taubaté-SP; São Paulo: PINDAMONHANGABA; 2015; Dissertação (Graduação) - Curso Farmácia; Faculdade de Pindamonhangaba.

CONAC 2018. Riscos da automedicação e o uso irracional de antibióticos. Disponível em: <https:// conaccones.com.br/2017/anais/anais/assets/uploads/trabalhos/07022017_210726.pdf. 2019.

COSTA, A.L.P.D.; SILVA JUNIOR, A.C.S. Resistência bacteriana aos antibióticos e Saúde Pública: uma breve revisão de literatura. Revista Estação Científica, UNIFAP, v. 7, n. 2, p. 45-77, mai./ago. 2017.

INSTITUTO FEDERAL DE EDUCAÇÃO, CIÊNCIA E TECNOLOGIA. Microbiologia geral. Disponível em: <http://estudio01.proj.ufsm.br/cadernos/ifgo/tecnico_acucar_alcool/microbiologia_geral.pdf>. Acesso em: 25 fev. 2019.

FERNANDES, L.C.L; BERTOLDI, Andréa D; BARROS, A.J.D. Utilización de los servicios de salud por la población cubierta por la Estrategia de Salud de la Familia. Revista de Saúde Pública, Rio Grande do Sul, v. 43, n. 4, p. 595-603, 2009.

FONSECA, A.L., Antibióticos na Clínica Diária. Rio de Janeiro: Epume, 1984, ed. 2, 208p.

FONSECA, A.L.D. Dicionário de especialidades farmacêuticas: Def. 37 ed. RIO DE JANEIRO/RJ: EDITORA DE PUBLICAÇÕES CIENTÍFICAS, 2008. 946 p.

HOWLAND, et al. Inibidores da síntese da parede celular; Farmacologia llustrada, 3 ed. São Paulo: Higienópolis, 2007, 253p.

JUNQUEIRA, L.C; CARNEIRO, J.; Células procariontes; Biologia Celular e Molecular, 6. Ed. Rio de Janeiro: Guanabara Koogan, 1997, 250p.

LIMA, R.R. et al. Inflamação em doenças neurodegenerativas: subtítulo do artigo. Revista Paraense de Medicina, Belém, v. 21, n. 2, p. 29-34, jun./2007. 
LOPES, H.L.; PEREIRA, J.B.; CARVALHO, M.R. O que sabem os utentes sobre antibióticos: Um estudo de investigação em duas Unidades de Saúde Familiar. Revista Portuguesa de Medicina Geral e Familiar, s/l, v. 31, n. 4, p. 248-254, 2015.

MATOS, C.R.C. Resistência bacteriana aos antibióticos como um problema de saúde pública - O papel do farmacêutico enquanto promotor de saúde. [Dissertação], Universidade Lusófona de humanidades e tecnologias, Lisboa. 2012.

NASCIMENTO, J.D.P; VALDÃO, G.B.M. Automedicação: educação para prevenção. CIEGESI, Goiás, s/n, s/v, p. 813-829, 2012.

NOGUEIRA, H.S., XAVIER, A.R.E.O., XAVIER, MAS., CARVALHO, A.A., MONÇÃO, G.A., BARRETO, N.A.P. Antibacterianos: Principais classes, mecanismos de ação e resistência. Revista Unimontes Científica, Montes Claros, v. 18, n. 2, p. 98 -108, 2006.

OLIVEIRA, A.C., SILVA, R.S.; Desafios do cuidar em saúde frente à resistência bacteriana: uma revisão. Revista Eletrônica de Enfermagem. 2008.

OLIVEIRA, M.D.C.; NETO, M.C.; SANTOS, O.F.P. Atualização em Insuficiência Renal - Nefrite Túbulointersticial aguda. Jornal Brasileiro de Nefrologia, Unifesp - SP, v. 22, n. 4, p. 260-276, 2000.

REIS, C.E. Estudo da Eficácia da Amoxicilina Incorporadas em membranas de látex. [Trabalho de Conclusão de Curso], Instituto Municipal de Ensino superior de Assis. 2015. 66 p.

SANTOS, S.L.F.D. et al. O papel do farmacêutico enquanto promotor da saúde no uso racional de antibióticos. Revista Ciência e Saúde, Universidade Estadual do Ceará, v. 6, n. 1, p. 79, 2017.

SILVA, J.C. et al. Prospecção tecnológica de alcaloides usados no tratamento da dor. Revista Geintec, s/l, v. 5, n. 3, p. 2284-2295, 2015.

SOUZA, M.V.; REIS, C.; PIMENTA, F.C. Revisão sobre a aquisição gradual de resistência de staphylococcus aureus aos antimicrobianos. Revista de Patologia Tropical, Universidade Federal de Goiás (UFG), v. 34, n. 1, p. 27-36, jan./abr. 2005.

TRINDADE, N.M.; CERDEIRA, C.D.; SANTOS, G.B. Avaliação do uso de antimicrobianos e perfil de usuários de uma farmácia do Sul de Minas Gerais. Revista da Universidade Vale do Rio Verde, Instituto de Ciências Biomédicas, UNIFAL-MG, v. 15, n. 1, p. 755-762, jan./jul. 2017.

WOKSEPP, H. Individualized treatment and control of bacterial infections. 2017. 94 f. Dissertação (Doutorado em Medicina) - Departamento de Medicina e Optometria, Linnaeus University, Kalmar, 2017.

ZUTION, J.R. In: Congresso nacional de conhecimento, 11', 2017. Porto Seguro/BA. 